\title{
CIUDADES DENTRO DE LA CIUDAD: \\ Futurismos del pasado en dos proyectos de vivienda \\ de Rogelio Salmona y Germán Samper.
}

\author{
Arq. Mg. William García Ramírez \\ Pontificia Universidad Javeriana - Bogotá \\ william.garcia@javeriana.edu.co
}

\begin{abstract}
RESUMEN
El tema de este artículo es la historia de dos "ciudades dentro de la ciudad" proyectadas por Rogelio Salmona y Germán Samper respectivamente, un balance historiográfico del sentido e importancia en el tiempo, de dos modos de concebir y proyectar la nueva ciudad de finales del siglo XX en Colombia. Tratándose de un balance comparativo, la hipótesis de investigación se sustenta en que estos dos proyectos de vivienda (Ciudadela Colsubsidio y Nueva Santa Fe de Bogotá), expresan dos modos de retomar la historia, como insumo para la proyectación de nuevos sectores de ciudad. El punto de partida se fundamenta en el entendimiento comparativo de dos modos de asumir la experiencia historiográfica de un viaje en común por Europa, como parte de las premisas que dieron lugar a unos modelos de ciudad, donde la incorporación del pasado como presencia viva, es uno de los principales leitmotiv utilizados por Salmona y Samper.
\end{abstract}

Palabras clave: Ciudades dentro de la ciudad, urbanismo, arquitectura latinoamericana, Colombia

\begin{abstract}
The theme of this paper is about the history of the two "Cities inside the city", designed by Rogelio Salmona and Germán Samper respectively. An historiographical balance of the sense and importance in the time, of two ways of conceiving and projecting the new city of ends of the 20th century in Colombia. Treating itself about a comparative balance sheet, the hypothesis of investigation is sustained in that these two projects (Ciudadela Colsubsidio and Nueva Santa Fe of Bogotá), express two manners of taking again the history, as input for the proyectación of new sectors of city. The point of view of this paper is based on the comparative understanding of two manners of assuming the historiographical experience of a trip jointly for Europe as part of the premises that gave place to a few models of city, where the incorporation of the past as alive presence, is one of the principal leitmotiv used by Salmona and Samper.
\end{abstract}

Key words: Cities inside the city, urbanism, latinoamerican architecture, Colombia 


\section{UN VIAJE, DOS VISIONES}

Rogelio Salmona y German Samper, hijos de la calle de Sevrés, emprenden en el verano de 1949, un viaje por Italia a solicitud de Le Corbusier. El objetivo era elaborar unos dibujos del casco histórico de varios pueblos italianos, para una ponencia del arquitecto a presentarse en el Congreso Internacional de Arquitectura Moderna (CIAM) de 1949 en Italia. Antes de iniciar el viaje, Le Corbusier les preguntaría a sus jóvenes discípulos si tenían cámara fotográfica, "una más o menos buena", respondería Samper; "déjela" les diría Le Corbusier, "Los arquitectos deben saber dibujar porque la única manera de analizar y estudiar una pieza arquitectónica es cuando el lápiz la raya en un papel. Usted tiene que hacer ahí, una operación de análisis de proporciones y de estructuras" (Samper, 2011:37). De acuerdo con German Samper, esta lección de arquitectura no era más que el reflejo de una experiencia autodidacta de Le Corbusier, pues sus croquis de viaje y bocetos de diseño son hoy en día, testimonio de los análisis practicados en sus viajes, como síntesis de una metodología aprendida a su vez, de uno de sus maestros: Charles L’Eplattenier

“Le Corbusier..., nos estimuló a Rogelio Salmona y a mí a dibujar todo lo que nos pareciera interesante. Esquematizar plantas, tomar medidas, realizar cortes, dibujar detalles, anotar observaciones. En síntesis, convertir una visita arquitectónica en una fuente de estudio". (Samper, 1986:9)"

Este verano por Italia, sería el primero de varios viajes que estos arquitectos realizaran, ya por separado, durante los años 50 y hasta su regreso a Colombia (Samper regresaría en 1957 y Salmona en 1958), viajes en los que conocerían de primera mano, un panorama urbano arquitectónico muy distinto al concebido por Le Corbusier en sus proyectos, panoramas de los que quedarían sendos testimonios a través de los dibujos y croquis de viaje realizados, los cuales expresan un modo de ver, pero también un modo de valorar la ciudad europea a través de los ojos de estos dos arquitectos colombianos. Estos viajes les permitirían a Samper y a Salmona, re-conocer a través de sus dibujos, las estructuras históricas sobre las que se fundamentaron algunas ciudades del pasado, viajes cuyo disímil impacto en los jóvenes arquitectos, vendría a evidenciarse posteriormente.

Mientras que Samper sería fiel a las orientaciones de su maestro frente al aprendizaje de la arquitectura por medio del dibujo, Salmona tomaría cierta distancia al respecto y asumiría la experiencia del dibujo desde un ángulo distinto. En palabras de German Téllez. "Este viaje será una enseñanza para Samper, y una confrontación para Salmona. Samper dibujará lo que vé; Salmona lo que siente" (Téllez, 2006:32) y si bien se trata de dos enfoques distintos, la trascendencia futura de estas lecciones de arquitectura, repercutirá en el modo de incorporar la historia como presencia viva dentro de sus obras de arquitectura, específicamente en los proyectos Ciudadela Colsubsidio y Nueva Santa Fe de Bogotá. Al revisar sus bitácoras de viaje, es evidente que, en tanto Samper se decanta por un análisis de detalle, cruzado entre plantas y perspectivas arquitectónicas, Salmona opta por la visión amplia y panorámica de la ciudad en su conjunto, por lo que el paisaje se constituirá en recurrente motivo en sus dibujos de viaje. Esta diferencia, en la escala de la mirada de los dos arquitectos, será premonitoria de los enfoques proyectuales en el modo de entender y proyectar una arquitectura para la ciudad.

Por lo tanto, el punto de partida de este artículo se fundamenta en el entendimiento comparado de dos modos de asumir la experiencia historiográfica de un viaje en común, por medio de los dibujos realizados en este viaje (y otros viajes posteriores durante su estancia en el despacho de Le Corbusier), como parte de las premisas que dieron lugar a unos modelos de ciudad, donde la incorporación del pasado como presencia viva, será uno de los principales leitmotiv utilizados por Salmona y Samper, para los proyectos Nueva Santa Fe de Bogotá (1983) y Ciudadela Colsubsidio (1985) respectivamente.

\section{RETORNO A COLOMBIA}

Una vez finalizada su estancia de trabajo con le Corbusier, las diferencias ideológicas entre Samper y Salmona en el modo de asumir y aplicar las enseñanzas de su maestro en territorio colombiano no podían ser más contrastantes. Mientras Samper inicialmente acoge los preceptos conceptuales y formales Corbuserianos para la elaboración de sus proyectos en el país, Salmona los reconoce tan solo para situarse 
en el extremo opuesto de su otrora maestro, pues "Para él la arquitectura del futuro (de 1958) en Colombia debía venir del país mismo, y en ningún caso de Le Corbusier." (Téllez, 2005:31)

Tres décadas después del primero de sus viajes por Europa, ambos arquitectos logran sendos encargos para el diseño de bastos proyectos de vivienda de clase media en Bogotá: Samper y el grupo de arquitectos de la firma de la que es socio - Esguerra Sáenz y Samper, estaría a cargo del diseño de Ciudadela Colsubsidio (1985-1994), un proyecto de 2.500 viviendas ubicado al occidente de la ciudad, previsto para albergar 12.000 viviendas; mientras que Salmona y el grupo conformado por los arquitectos Julián Guerrero, Jaime Camacho, Pedro Mejía y Arturo Robledo, se encargaría del diseño de la Nueva Santafé de Bogotá (1984-1994), un proyecto previsto para albergar 2.000 viviendas, en un lugar próximo al centro histórico de la ciudad. Ambos proyectos se concebirían bajo la noción de "ciudades dentro de la ciudad", una política adoptada por el estado colombiano, que, en contravía de las vastas urbanizaciones construidas en el país y en Latinoamérica, en las que se construían viviendas, pero no ciudad, promovía la creación de grandes tejidos urbanos, en los que se integraba la vivienda, junto a variados equipamientos cuyas funciones complementaban las necesidades propias de los nuevos habitantes, sin tener que desplazarse fuera del entorno donde residían; nuevas "ciudades" cuyo modelo se fundamentaba en el diseño de espacios públicos complementarios, entendidos como conformadores de espacios de uso colectivo de los nuevos residentes.

\section{CIUDADES DENTRO DE LA CIUDAD}

Ciudades dentro de la Ciudad, fue la política de desarrollo urbano adoptada por el estado colombiano como respuesta al crecimiento espontáneo de las ciudades en las periferias, producto del fenómeno migratorio del campo a la ciudad, pero también, como contrapropuesta al modelo de crecimiento de las ciudades a partir de zonificaciones urbanas de tipo funcionalista. Una política adoptada bajo la presidencia de Alfonso Lopez Michelsen (1974-1978) consistente en un modelo sustentado en el desarrollo integral de sus habitantes mediante el diseño de un esquema de ciudad relativamente autosuficiente y "lo suficientemente grande para ofrecer las inquietudes, el movimiento y las oportunidades que el hombre desea, pero al mismo tiempo, debe ser lo suficientemente pequeña para que el individuo no se pierda en la multitud. Es decir que tanto los estímulos como la identidad individual son necesarios". En síntesis, se trata de un modelo de desarrollo que planteaba re-distribuir las funciones básicas de la ciudad, a partir de la generación de centros alternos planificados, en los que se integraban, además de la vivienda, servicios comunitarios, educativos, comerciales y de trabajo. En este sentido, se trata de un modelo de desarrollo que promueve la autonomía en el funcionamiento de ciertas áreas de ciudad, evitando la concentración de funciones -generalmente de tipo administrativo- en un mismo lugar, lo que evita además, grandes desplazamientos de los ciudadanos entre sus lugares de habitación y estos centros administrativos. Esta política, adoptada por el Departamento Nacional de Planeación hacia 1974, e implementada en Colombia por entes de carácter privado como las Cajas de compensación familiar e instituciones públicas como el Banco Central Hipotecario (B.C.H.), se empieza a traducir en hechos concretos hacia 1976, cuando se encarga a los arquitectos de la firma Obregón \& Valenzuela, un estudio preliminar que posteriormente daría lugar al proyecto final para la Nueva Santa Fe de Bogotá (1984), un proyecto concebido bajo la noción de Ciudad dentro de la ciudad, y al cual le seguirían otros grandes emprendimientos en el país, - la mayoría a cargo del B.C.H.-, como Ciudadela Real de Minas (Bucaramanga), un proyecto de Germán Samper que se considera antecedente a Ciudadela Colsubsidio, Nueva Villa de Aburrá (Medellín), Ciudad Tunal (Bogotá), Ciudad Salitre (Bogotá), Ciudadela Chipichape (Cali), entre otros.

Si bien el surgimiento del concepto de Ciudades dentro de la ciudad, se produjo - como ya se anotaba a mediados de la década de 1970-, su aplicación efectiva en el país solo vendría a producirse durante la década de 1980. Este desfase cronológico implicó la concepción de unos proyectos urbanos de los años 70 , materializados en su arquitectura, dentro de los postulados teóricos del naciente post-modernismo de los años 80 y 90, un posmodernismo que enfatizaba en considerar la arquitectura como un hecho cultural, esto es "como perteneciente a un entorno ... donde la memoria y la historia hacen parte de su constitución."(García, 1997:47) En Colombia, la aceptación de la arquitectura como hecho cultural llevó a la mayoría de los arquitectos a indagar modos de expresar una conciencia de cultura en el desarrollo de sus arquitecturas. En el caso de Salmona y Samper, las impresiones y aprendizajes logrados en su periplo por Europa se traducirían décadas después, en dos estrategias diferentes en este entendimiento de la arquitectura como hecho cultural que, sin embargo, tienen un mismo punto de partida: la historia. 


\subsection{CIUDADELA COLSUBISDIO: LA CIUDAD QUE EVOCA}

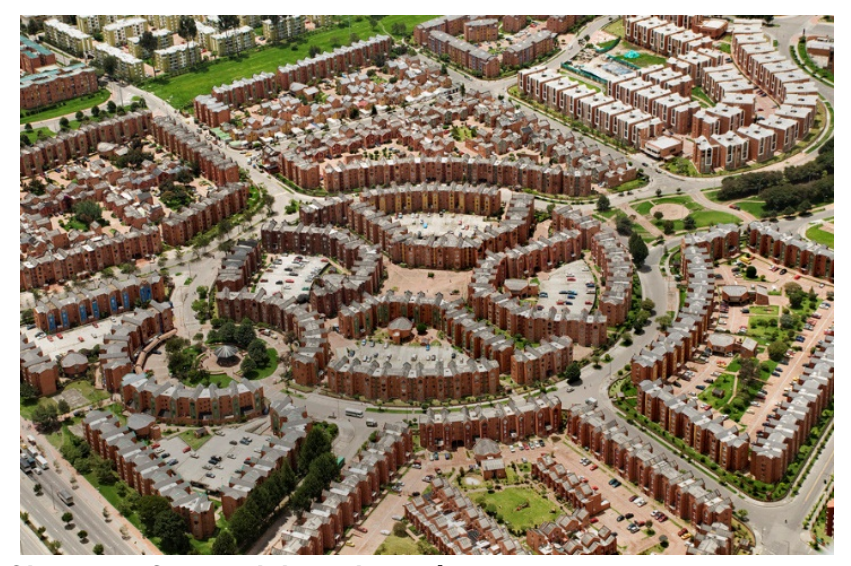

Ciudadela Colsubsidio - Vista Aérea 2018. Foto: Eduardo Mora

Dos exigencias y una lección del pasado confluyeron en el enfoque general para el diseño de la Ciudadela Colsubsidio. Las exigencias estuvieron determinadas por la Oficina de Planeación Distrital y la entidad promotora - Caja de Compensación Familiar Colsubsidio- que demandaban para el diseño de la ciudadela, criterios aparentemente irreconciliables entre sí. Mientas que la Oficina de Planeación exigía que en el terreno a urbanizar se dispusiera de una serie de vías vehiculares de importantes dimensiones que dieran conexión y continuidad entre el nuevo desarrollo y los barrios adyacentes, la entidad promotora demandaba "la creación de un conjunto, a escala de barrio que integrara no solamente unidades de habitación sino todos los servicios para la vida cotidiana, que mejorarán la calidad de vida de sus futuros habitantes, como son: viviendas, sala cunas, colegios, centros de salud, supermercados y áreas recreativas",(Samper, 2003: 173) en síntesis un barrio donde se privilegiara la escala y el ser humano, y en el que sin embargo existieran vías vehiculares de gran rango que conectaran rápidamente el nuevo desarrollo con las vías circundantes.

(1)
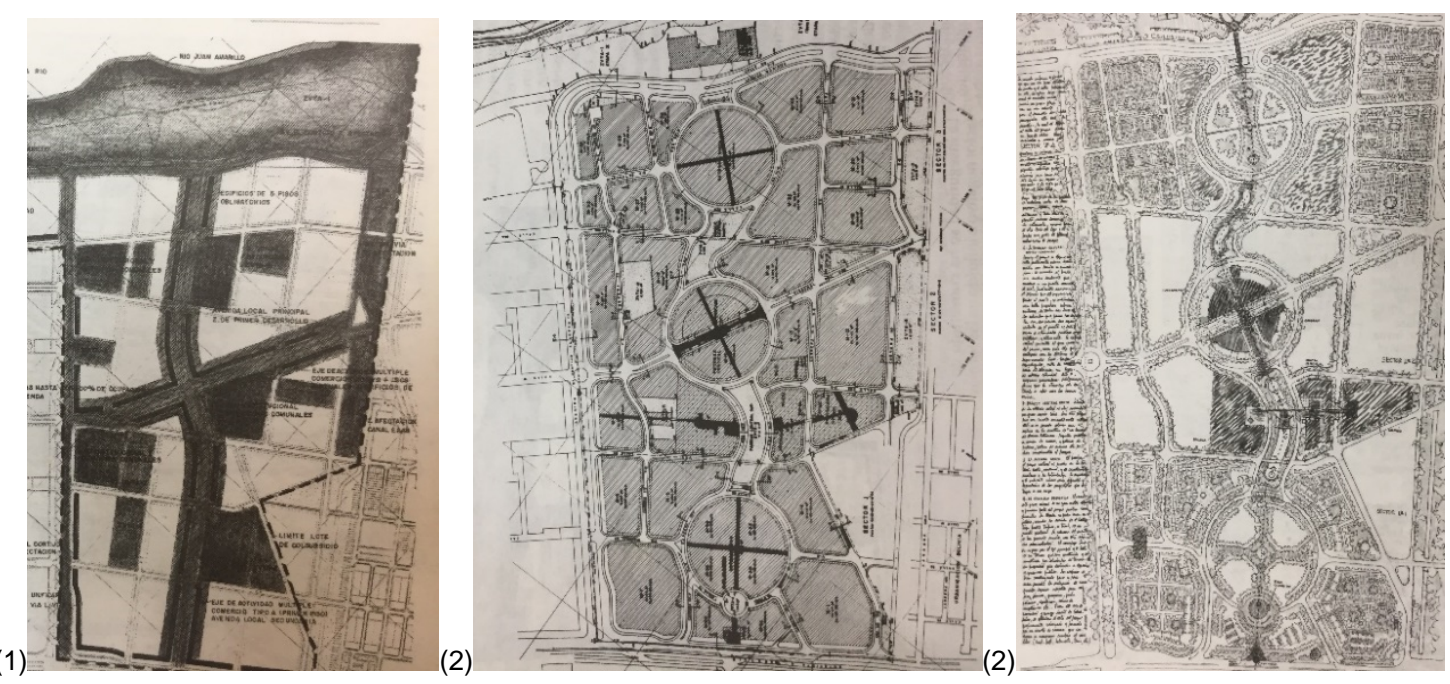

(1) Esquema urbano previsto por el departamento de Planeación distrital para el área donde se construiría la Ciudadela Colsubisidio vs. (2) Diseños finales para la ciudadela. Imágenes Libro Recinto Urbano - German Samper

En medio de esta aparente incompatibilidad, una lección del pasado se erigió como solución de conciliación entre las exigencias de la modernidad (el automóvil) y los requerimientos de una vida tranquila y sosegada. Esta enseñanza del pasado es nuevamente mencionada por German Samper en su libro La arquitectura y la ciudad. Apuntes de Viaje (Escala 1986), a partir de las experiencias de viaje que realizara por Europa, iniciadas con el viaje que realizara junto a Rogelio Salmona en 1949 y en el que Samper reconoce el profundo impacto que le produjo el diseño de una plaza de Bergamo (Italia) en la que "aparece una interpenetración del espacio público y el privado, que poco se usa en la arquitectura contemporánea" (Samper, 1986:11).

Esta particularidad en el diseño de la plaza, abre para Samper la posibilidad de conciliar actividades aparentemente divergentes, como podría ser la integración entre una circulación peatonal y una vehicular, 
utilizando para ello la estrategia que se adopta en la plaza de Bergamo de interpenetrar espacios públicos en espacios privados. Aplicado al proyecto de Ciudadela Colsubsidio, esta estrategia le permite al arquitecto, integrar sin mezclar diversas actividades y circulaciones, que de otra manera hubiesen resultado caóticas. Una lección del pasado que para Samper se constituyó en una metodología proyectual a partir del dibujo, tal como el mismo lo explica:

"Es un proceso dialéctico en el que lo que uno ve, se convierte en experiencia visual para cuando se diseña, y cuándo se diseña se adquieren compromisos que generan intereses para la búsqueda de espacios afines. Los viajes orientan nuestros diseños, y estos orientan los viajes venideros" (Samper, 1986:11)
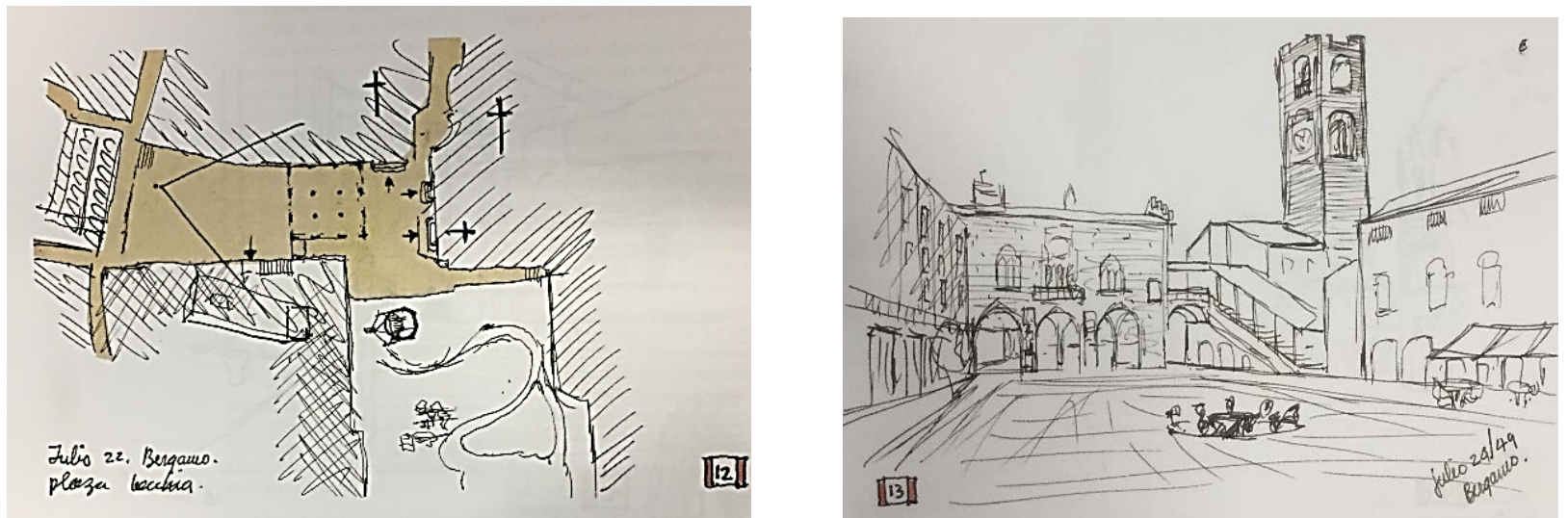

Dibujos de Germán Samper. Plaza vecchia. Planta y perspectiva. Bergamo, Italia 1949. Imágenes tomadas del libro: A dibujar se aprende dibujando - Germán Samper

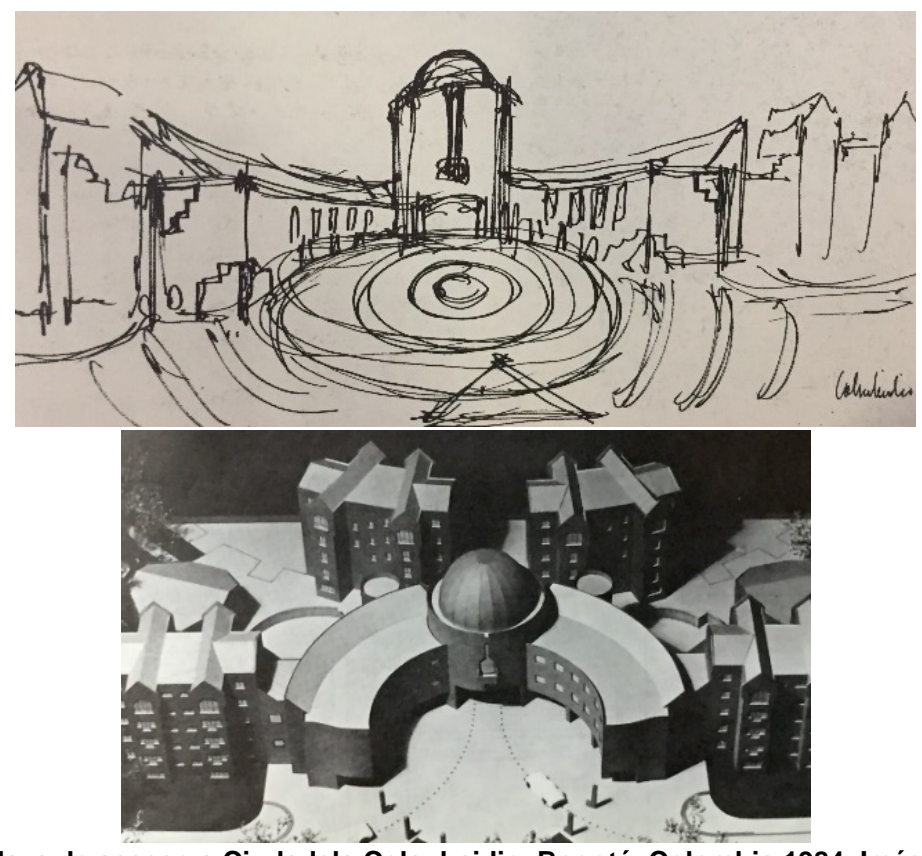

Dibujo y Maqueta Plaza de acceso a Ciudadela Colsubsidio. Bogotá, Colombia 1984. Imágenes Revista Escala

En las bitácoras del arquitecto Samper, se encuentran dibujos que ilustran el paso de pequeñas calles sobre espacios privados, esta condición propia del azar constructivo medieval es analizada con ojos contemporáneos por Samper como una oportunidad de diluir las fronteras entre espacios privados y espacios públicos, logrando así una ciudad más igualitaria. Esta actitud, que pone en entre dicho la propiedad privada, resulta contestataria para una sociedad que cuestiona la intromisión de lo público en la propiedad privada.

Ejemplo aplicado de esta metodología proyectual lo constituyen los accesos y pasos a algunas de las viviendas, tanto unifamiliares como multifamiliares en la Ciudadela Colsubisdio, así mismo, el acceso original a la ciudadela (no construido), configurado como una puerta urbana de acceso permeable a la plaza principal del conjunto, ejemplos en los que se evidencia un modo de retomar la historia, a partir de la evocación de operaciones formales propias del pasado y retrotraídas en tiempo presente. 

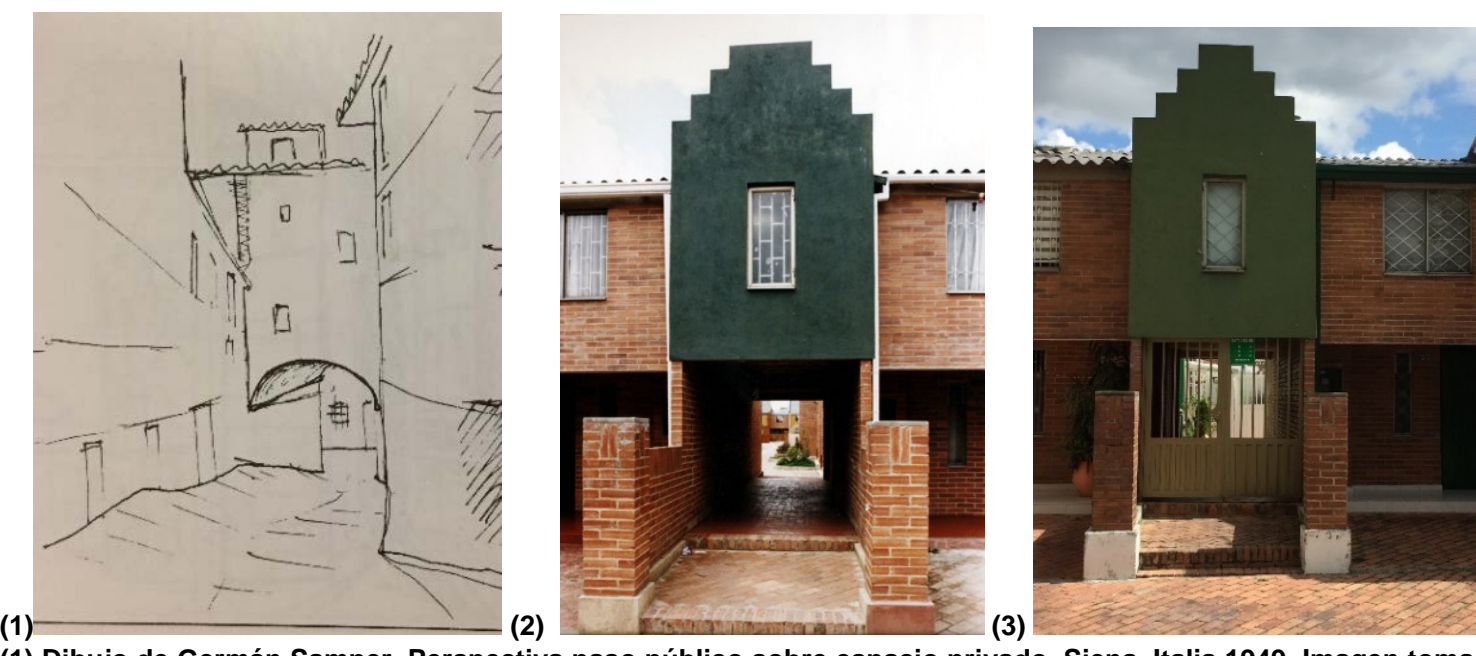

(1) Dibujo de Germán Samper. Perspectiva paso público sobre espacio privado. Siena, Italia 1949. Imagen tomada del libro: La arquitectura y la ciudad. Apuntes de viaje. (2) Pasos públicos sobre espacio privado - Ciudadela Colsubsidio -1992 . Imagen tomada de la Revista Habitar (3) Imagen de 2018. Foto: Arq. William García R

Otra, es la historia que cuentan las volumetrías de los edificios de apartamentos en la ciudadela Colsubsidio, de acuerdo con Samper: "El tratamiento vertical condujo a remates de cubiertas en dos aguas perpendiculares a la fachada... Este tipo de remate es coincidencialmente el usado por la arquitectura del medioevo en Europa y adoptado en gran medida en Bogotá con el llamado estilo inglés, que es una importación del Tudor, pero este se volvió característicamente bogotano. Este tipo de tejado se denomina "hastial" y su término fue rescatado del vocabulario de los viejos tratados de arquitectura" (Samper,1997:281). De esta manera, Samper justifica el diseño volumétrico para los edificios de vivienda multifamiliar; una mezcla de historias y tiempos históricos que más allá de un efecto estético, buscan generar unidad en el conjunto y a la vez, una diversidad que evitara la triste monotonía que suele caracterizar algunas de las urbanizaciones construidas en el país durante el periodo correspondiente al movimiento moderno.
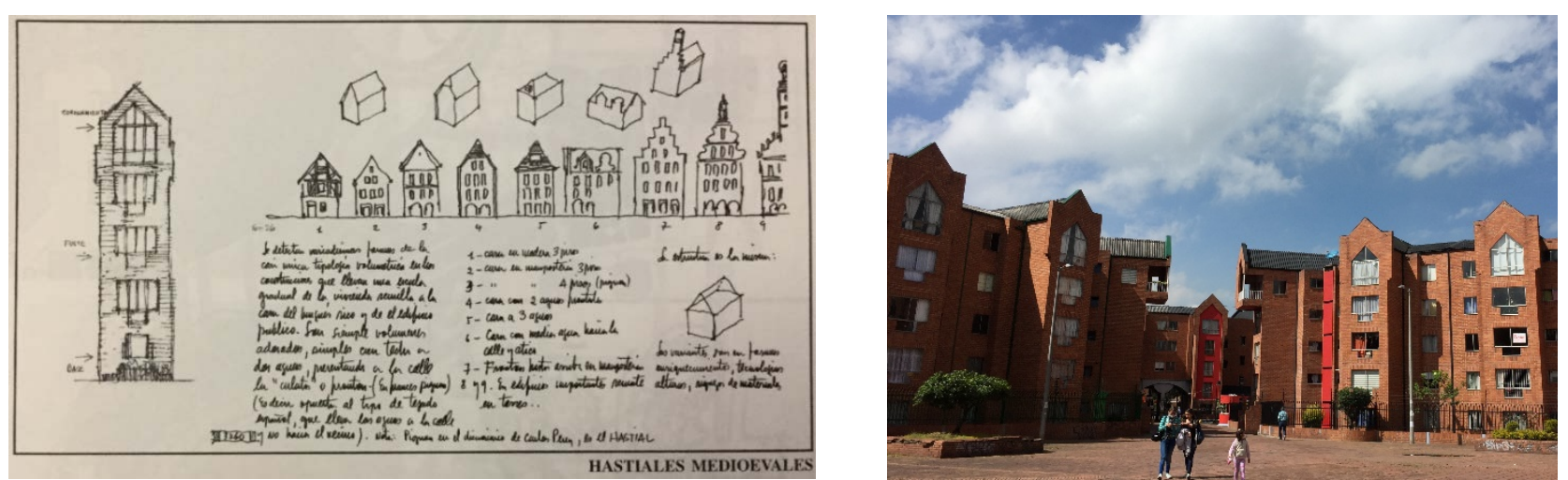

(1) Hastiales Medioevales. Dibujo de Germán Samper. Imagen tomada del libro Recinto urbano (2) Vista general Ciudadela Colsubsidio (2018) Foto: William García R

Transcripción de la nota al interior de la imagen: "Se detectan variadísimas formas de la casi única tipología volumétrica en las construcciones que llevan una escala gradual de la vivienda sencilla a la casa del burgués rico y del edificio público. Son siempre volúmenes adosados, simples con techo a dos aguas, presentada a la calle..." (Samper, 2003: 177)

Por otra parte, la decisión de paramentar los edificios tiene una doble explicación: según Samper, "es un rechazo a los edificios sueltos e independientes de la calle, que formuló el movimiento moderno." (Samper, 1997:275) Sin embargo, también es evidente que esta oposición al movimiento moderno se hace a partir de una lectura histórica de la ciudad, y siguiendo la idea de tener frentes de fachada de idéntica proporción, pero con fachadas diferentes a fin de otorgar variedad y riqueza al conjunto. 

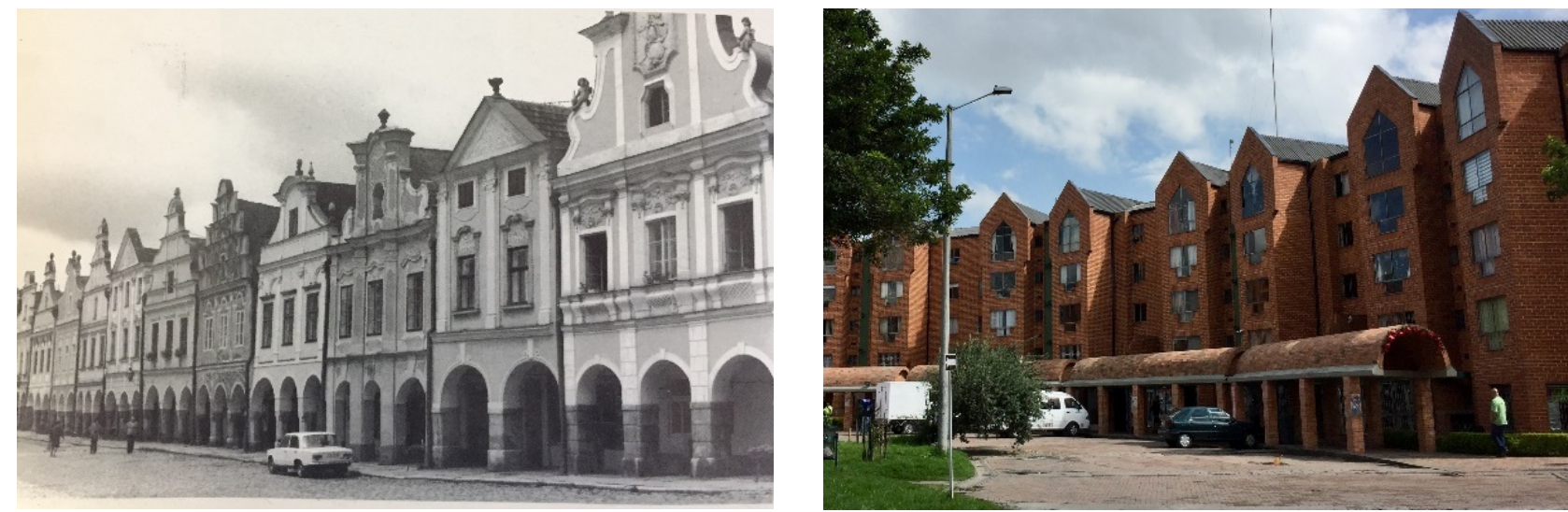

Comparativa: Imagen citada por G Samper en su libro Recinto Urbano, para explicar la necesidad de contar con una variedad volumétrica en las unidades de vivienda multifamiliar vs. Diseño Ciudadela Colsubsidio (2018). Foto: Arq. William García R

Respecto al lugar seleccionado para Ciudadela Colsubsidio, cabe anotar que se trataba de una vasta extensión donde nunca se había construido nada, podría decirse que se trataba de un lugar "sin historia", o por lo menos sin una memoria significativa. Este hecho, sumado a la exigencia del promotor de crear un barrio con identidad, llevó al arquitecto a buscar una estrategia que, salvando con éxito el vacío que implican los falsos históricos en arquitectura, le infunde a este territorio un carácter particular, por medio de una serie de evocaciones de tipo historiográfico con las que las que se buscaba que los futuros habitantes pudiesen identificarse o por lo menos les resultaran reconocibles y familiares.

En síntesis, podría afirmarse que las principales operaciones formales que Samper utiliza tanto en el diseño arquitectónico como en el diseño urbano de Ciudadela Colsubsidio constituyen un modo de evocar la historia, es decir, de rememorar, "de recordar una cosa a otra por su semejanza"(Moliner, 2003), una estrategia con la que, conforme a los dictámenes posmodernos, se le confiere un valor cultural a la arquitectura, tomando como punto de partida el reconocimiento de unos valores urbanos y formales del pasado. En este sentido, Ciudadela Colsubsidio, logra una manera de evocar la historia haciendo alusión de tipologías pretéritas como estrategia para que el hilo cultural de las influencias arquitectónicas no se pierda, todo, con el fin de brindarle a estos espacios un sentido de identidad y escala donde primen las relaciones humanas. Ahora, que la selección de estas influencias sea de carácter europeo y no latinoamericano o colombiano se explica por la formación recibida por Samper en la lectura y análisis de antiguas arquitecturas europeas, pero principalmente, por un modo de valorar la historia de estas arquitecturas, en el que renunciando a los frecuentes espejismos que ofrece la "innovación" en arquitectura, se decanta por la aplicación de ideas ya comprobadas en otras latitudes.

Visto como metodología, es evidente que fue a través del dibujo cómo se filtraron las experiencias inconscientes de un viaje, en realidades conscientes dentro de un proyecto urbano arquitectónico. Una visión proyectual en la que se retoma la historia como campo de aprendizaje para un diseño futuro. Que en el proyecto se apele a operaciones formales tomadas de referentes históricos de un modo cercano a lo literal, es comprensible frente a las expectativas que se tenían de la arquitectura en el contexto latinoamericano de 1985, pero ya no lo es tanto desde una perspectiva contemporánea, con la que rápidamente se calificaría este proyecto como de tendencia historicista, dado que estos recuerdos espacio-temporales de carácter arquitectónico, retrotraídos en tiempo presente pueden resultar para algunos ya anacrónicos. Pero más allá de esta discusión teórica, lo palpable es la calidad de vida y el buen estado de las arquitecturas en la Ciudadela Colsubisidio, después de más de 25 años de estar habitada, tal como se verificó en la visita de campo realizada en 2018. El respeto y cuidado de la arquitectura original por parte de sus habitantes, así como los modos en que se han venido adoptando y adaptando las viviendas tanto unifamiliares como multifamiliares a los requerimientos de la vida contemporánea, en una permanente integración con los barrios adyacentes, atestiguan el positivo impacto de esta arquitectura en las nuevas generaciones de familias que allí habitan. 


\subsection{NUEVA SANTA FE DE BOGOTA - LA CIUDAD QUE INVOCA}

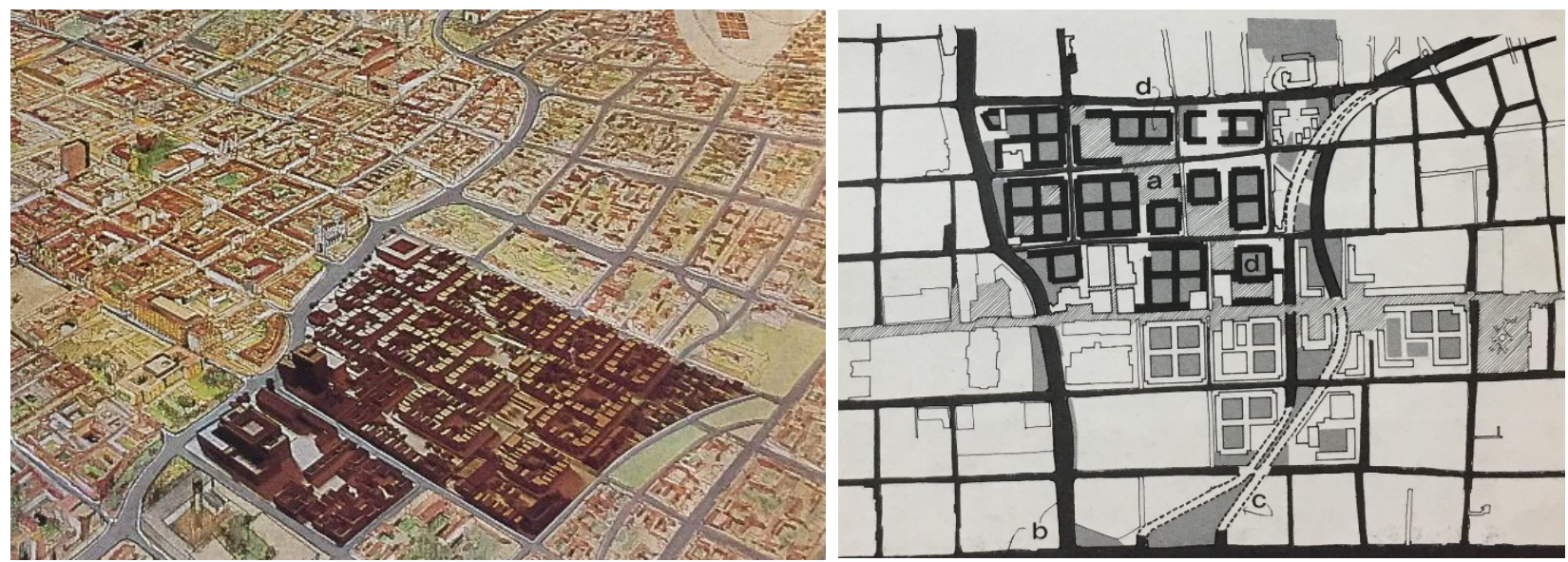

Nueva Santa Fe de Bogotá - perspectiva y planta general del proyecto. Imágenes tomadas del libro: Plan de renovación urbana Nueva Santa Fe de Bogotá (1986)

Como su nombre lo indica, este vasto proyecto de vivienda aludía a un sentido de refundación de la ciudad en pleno centro histórico. En efecto, la orientación dada al proyecto por parte de la entidad promotora - El Banco Central Hipotecario B.C.H. - fue el de un "plan de renovación urbana", un enfoque altamente cuestionado en su momento, debido a que para lograr tal "renovación urbana" fue necesario iniciar un lento proceso de demolición del área correspondiente a 9 manzanas ubicadas en el costado sur oriental del Palacio presidencial, donde se iba a construir el proyecto, y que en su momento estaban ocupadas por viviendas unifamiliares en muy mal estado -algunas convertidas en inquilinatos - de los siglos XVIII y XIX.

Aunque se trataba de un proyecto de renovación urbana, las directivas del B.C.H. afirmaban además, que la Nueva Santa Fé de Bogotá: "No solamente gozará de la organización del concepto de "ciudad dentro de la ciudad" sino que se tendrá acceso directo a la principal malla vial de la capital, con conexiones rápidas a las zonas residenciales, institucionales e industriales del área metropolitana" $(\mathrm{BCH}, 1986: 4)$ Por lo tanto, el reto que se planteaba con el diseño de esta nueva "Ciudad dentro de la ciudad" era el de crear un nuevo centro de actividades urbanas que respondiese a las necesidades contemporáneas, pero que a la vez, se contextualizara e integrara dentro del centro histórico de la ciudad.

Tanto por la ubicación del proyecto, como por el contexto circundante, pleno de arquitecturas de los siglos XVIII y XIX, fue evidente que el tema de la historia sería determinante en las decisiones urbanísticas y arquitectónicas que darían lugar al proyecto final. Sin embargo, y contrario a las francas evocaciones históricas que Samper et al, practicaran en el diseño de la Ciudadela Colsubsidio, en las que se evoca la historia para hacer un llamado de "Io que se ve, pero ya no está", es decir, los recuerdos de un pasado vivido por su autor: German Samper y expresados en sus dibujos; el equipo de Salmona et al, opta por invocar la historia como método para rememorar la historia del lugar prexistente al proyecto: el barrio Santa Bárbara. En este sentido, el acto de invocar en arquitectura implicó hacer un llamado a lo que "no se ve, pero está", en este caso, la presencia del antiguo barrio santa Bárbara, con el fin de mantener a través de la nueva arquitectura, una memoria colectiva del antiguo barrio, el cual, a pesar de no existir más físicamente, sí permanece en la memoria de los bogotanos, más aun tratándose de un espacio próximo al centro histórico de la ciudad, todo lo cual llevó a una lectura más conceptual y, por ende, menos formalista de la historia del lugar, que se traduciría en concordancia con los antecedentes históricos del lugar, en las siguientes decisiones y operaciones proyectuales para el proyecto de la Nueva Santa Fe de Bogotá:

1. Conservar la morfología de manzana y el trazado de damero histórico, propios del sector 


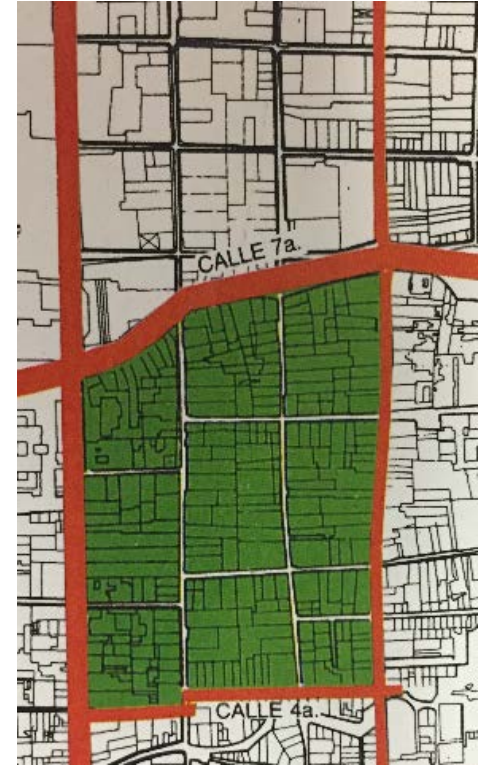

(1) Trazado pre existente

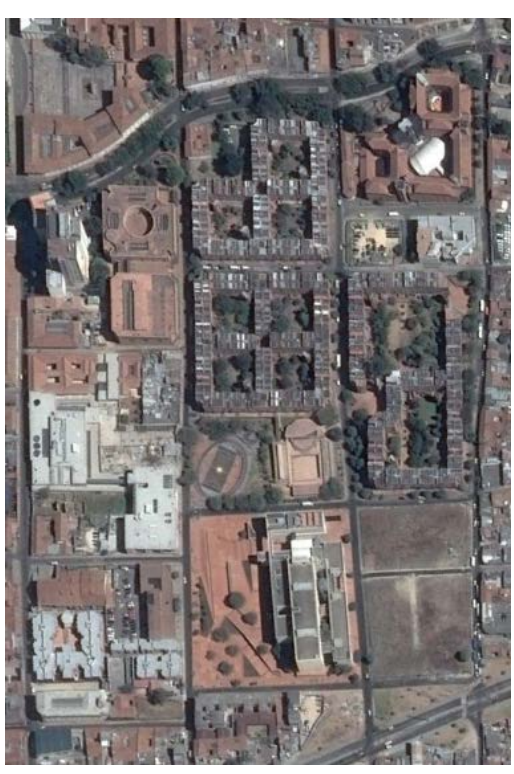

(2) Ocupación propuesta Nueva Santa Fe

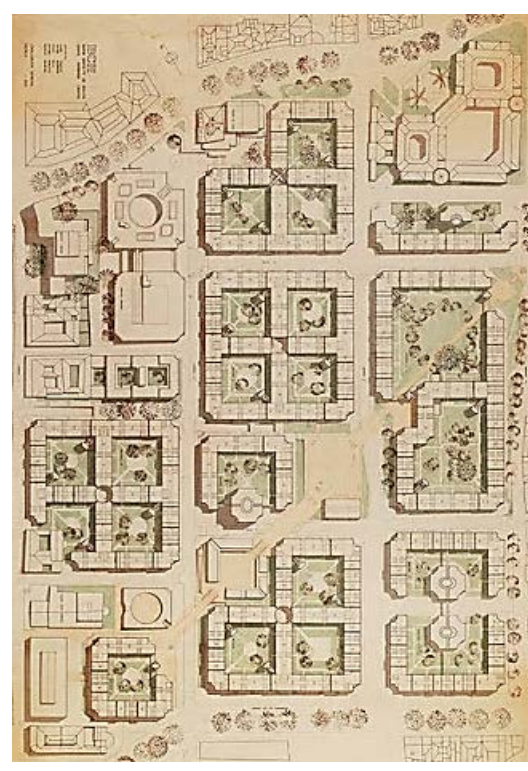

(3) Área finalmente construida (2018)

(1) Imagen tomada del libro Plan de renovación urbana Nueva Santa Fe de Bogotá (1986)

(2) Imagen tomada de la página web de la Fundación Rogelio Salmona

(3) Imagen tomada de Google Earth

2. Generar un perfil de vía en el que se recuperaran los andenes cubiertos característicos, de las antiguas viviendas del barrio Santa Bárbara.

3.
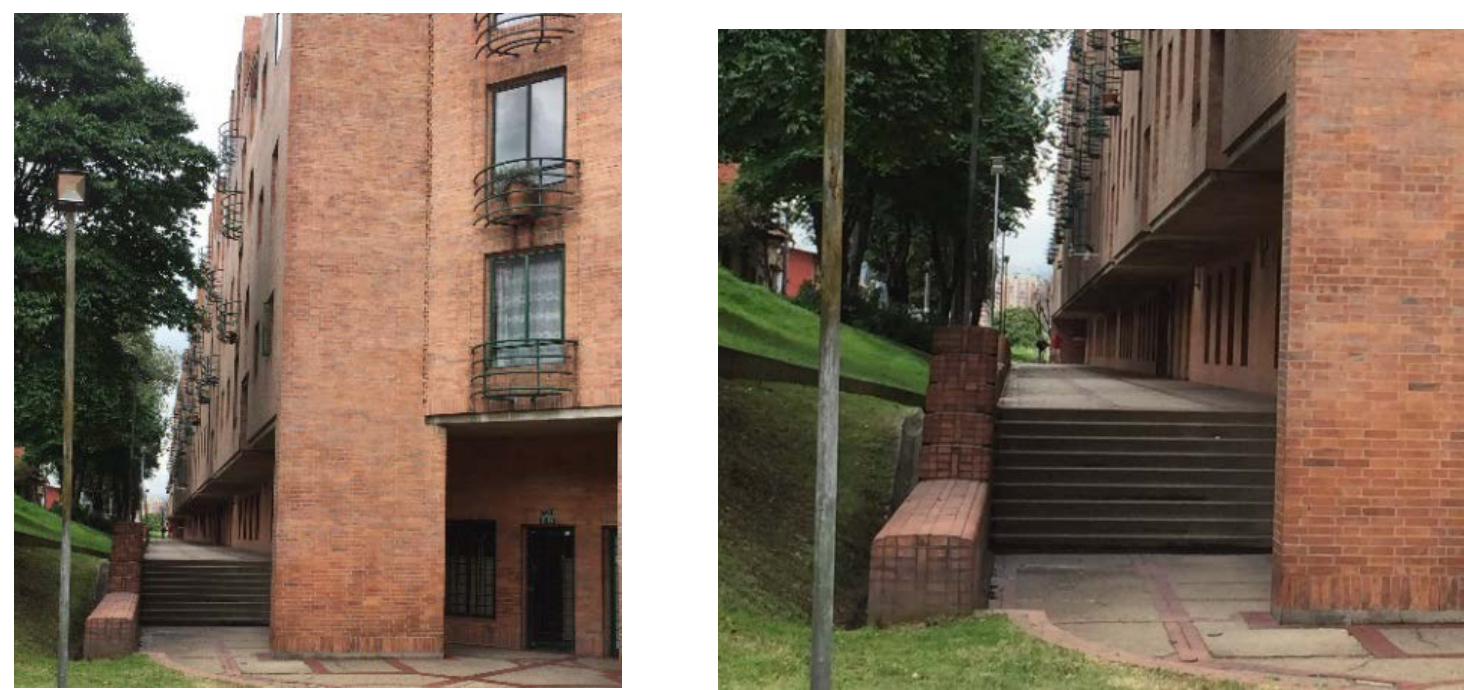

Nueva Santa Fe de Bogotá - Primer nivel de acceso cubierto. - Detalle ampliado. Fotos: Arq. William García R

4. Conformar un centro de manzana vacío como área verde común, con el que se rememoraran los antiguos solares traseros de las viviendas, utilizados entonces como áreas libres 

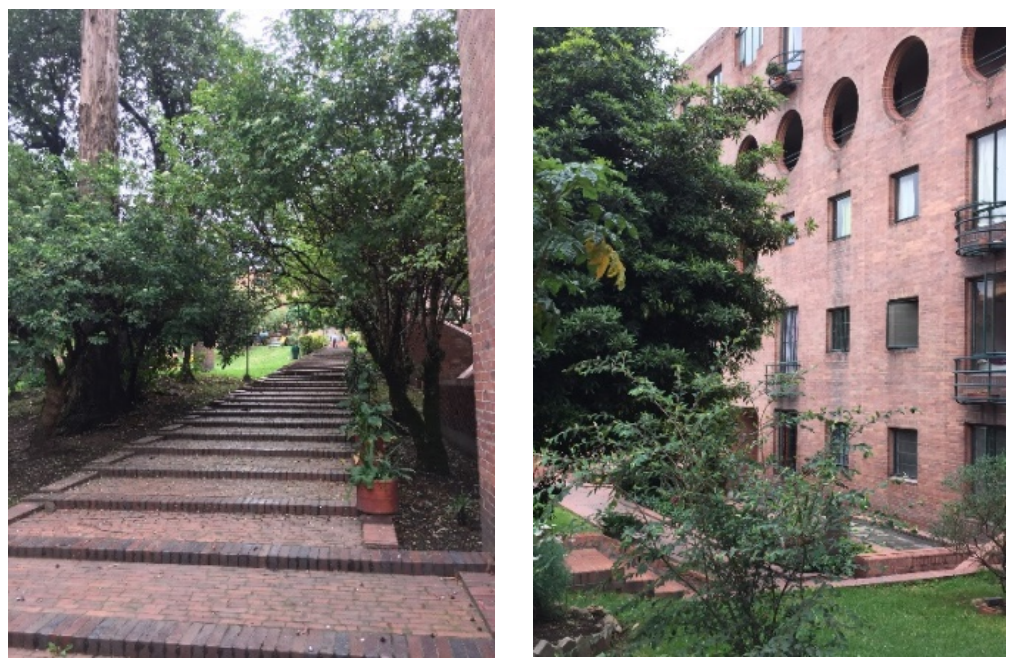

Centro de manzana con sendero peatonal - Vista interior de la manzana. Fotos: Arq. William García R

5. Un centro de manzana que permitiera que las viviendas tuviesen doble fachada, una que mira a la calle y otra que mira hacia este centro que conforma un patio común.
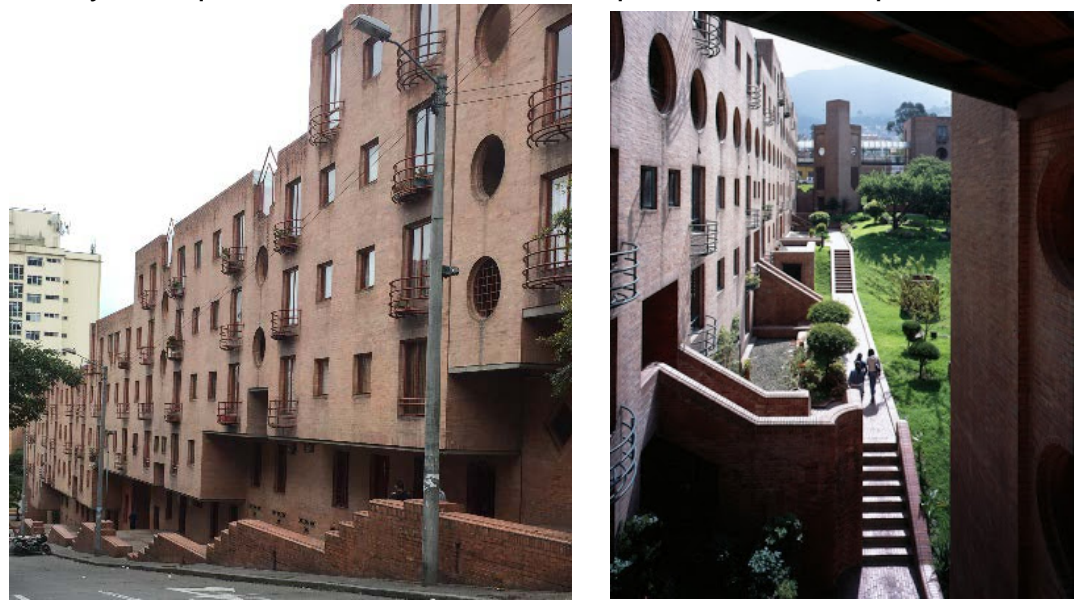

(1) Manzana 1 Norte - Fachada Exterior. (2) Manzana 1 Norte - Fachada Interior. Foto 1: Arq. William García R. Foto 2: Fundacion Rogelio Salmona

6. Utilizar los primeros pisos de los edificios como área comercial, mediante la implementación de pequeños locales que generaran actividades a escala barrial como tiendas y ventas de artesanías.

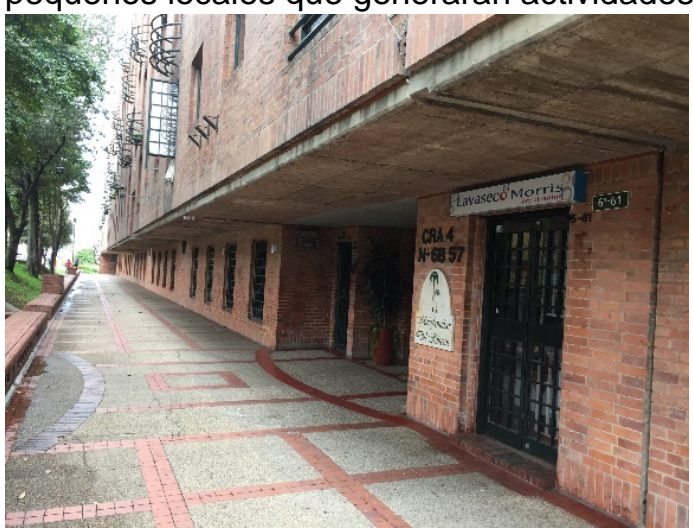

Nueva Santa Fe de Bogotá - Primer nivel de acceso con locales comerciales. Foto: Arq. William García R

7. Generar espacios de uso público tanto en el perímetro de las manzanas de vivienda como al interior de las mismas, a fin de integrar la nueva intervención con el contexto pre existente. 

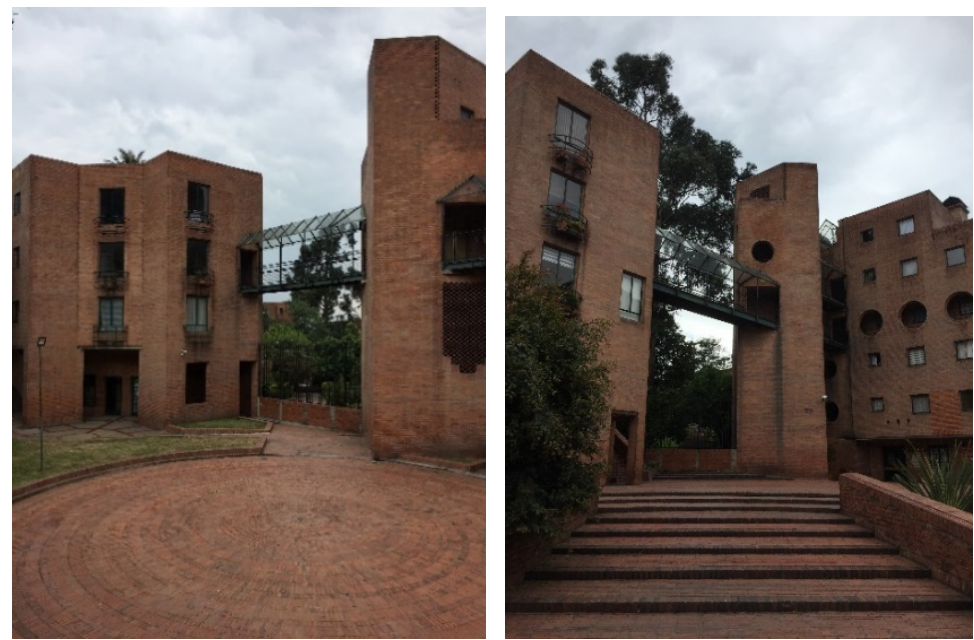

Nueva Santa Fe de Bogotá - Esquinas de las manzanas con plazoletas. Obsérvese el cerramiento mediante muros que posteriormente los habitantes efectuaron en las equinas de los bloques. Fotos: Arq. William García $\mathbf{R}$

Por otra parte, la experiencia de dibujo de Salmona en el viaje que realizara con Samper por Europa, también tendría una importante influencia sobre sus proyectos futuros. Como se mencionaba, mientras que Samper hace una lectura de detalle acerca de las ciudades antiguas, a través de operaciones formales puntuales que allí acontecen, Salmona opta por hacer una lectura panorámica de estas ciudades, una visión paisajística que le permite entender la arquitectura de la ciudad en su conjunto como un todo y no sólo como partes aisladas. Esta visión se extendería posteriormente en otros viajes que el arquitecto realizaría ya por separado y en la que tercamente insistiría en esta visión de la ciudad en su conjunto. En palabras de Germán Téllez: "El arte medieval ... fue una primera fascinación para Salmona.... Luego hay un viraje considerable hacia el espectáculo del paisaje urbano: las siluetas ricamente estructuradas de Barcelona, las ciudades marroquíes y tunecinas, las ciudades medievales italianas en especial (Venecia, Perugia, Asis, Arezzo, Siena...) constituyeron para Salmona una experiencia destinada a acompañarlo durante el resto de su existencia. Esas impresiones dibujadas cobrarán al paso de las décadas, inusitada importancia premonitoria, y estarán presentes, en cierto modo sutil e indirectamente en sus actitudes de diseñador". (Tellez,2006:32)
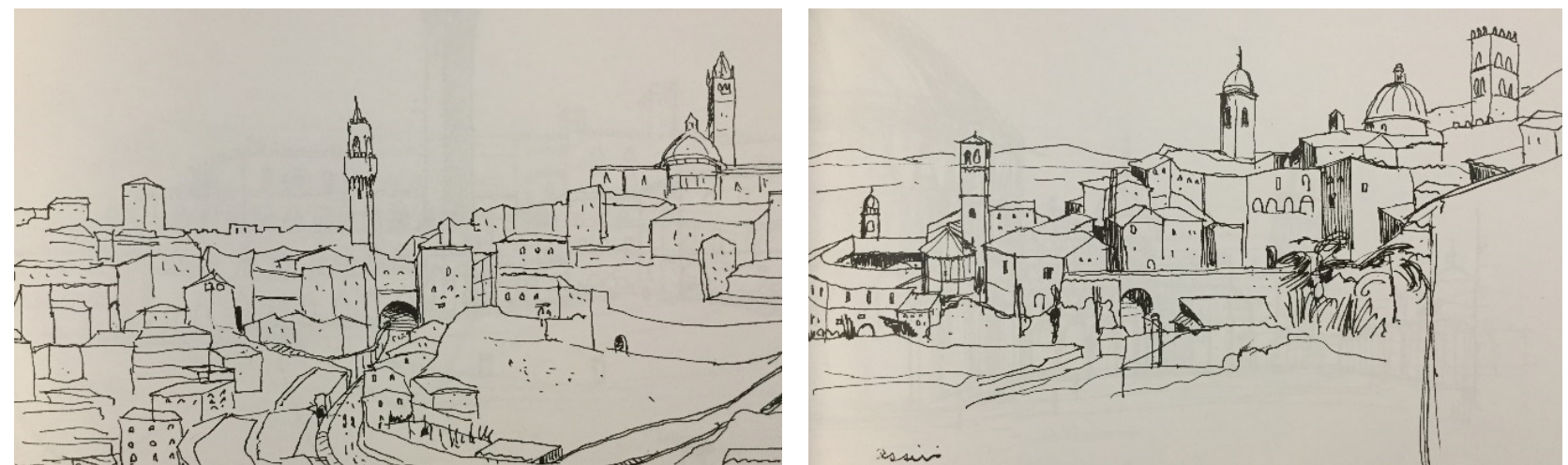

Rogelio Salmona - Dibujos de los paisajes de Siena y Asis, en su viaje por Italia (1951) . Imágenes tomadas del libro: Rogelio Salmona Obra completa 1959 / 2005

Sobre esta aproximación paisajística a la arquitectura de las ciudades, Salmona afirmaría posteriormente:

"El paisaje del lugar arquitectónico es la visión de conjunto de ese lugar con toda su arquitectura. El paisaje se destruye cuando la unidad se interrumpe. Cuando los materiales inapropiados no se componen al espíritu de la forma; cuando se olvida la historia que dio unidad al lugar;... cuando en su elaboración dejan de primar los aspectos comunitarios, el espacio público y la ciudad; ...cuando la arquitectura deja de crear espacios que evoquen, que extrañen, que encanten y sorprendan...el paisaje se destruye, el lugar deja de ser significativo y la ciudad se deteriora"(Salmona, 1990: 24)

Varios aspectos se desprenden del análisis planteado por Salmona acerca del paisaje arquitectónico, el primero y más evidente es el de valorar la arquitectura proyectada por su relación con la ciudad existente y la unidad del paisaje que se configura como resultado de esta valoración. De esta manera, se prioriza la armonía 
del conjunto arquitectónico por encima del valor de la individualidad de las partes, a fin de darle continuidad al paisaje arquitectónico, y enriqueciéndolo con nuevos aportes que, ante todo, no ignoren la historia que dio unidad al lugar. Esta conciencia sobre la importancia de una visión de conjunto de la ciudad quedaría testimoniada ya, desde los paisajes que reiteradamente Salmona hiciese de varias ciudades, durante su periplo por Europa (1949-1958), la que se materializaría posteriormente en el carácter de lo urbano en el proyecto de Nueva Santa fe de Bogotá, como medio y estrategia para invocar una arquitectura que rinda homenaje a la historia del lugar. Esta estrategia, que busca materializar lo que conceptualmente Salmona se proponía a través de su noción de Paisaje Arquitectónico, apela a una preocupación de fondo, reiterada en otros tantos proyectos del mismo autor, y que derivaría en uno de los principales postulados conceptuales de Rogelio Salmona: propender por una arquitectura que haga ciudad.

Resta por dilucidar acerca de los aspectos propiamente arquitectónicos del proyecto de la Nueva Santafé de Bogotá en relación con la historia del lugar, al respecto, es claro que el nuevo proyecto evita adaptar elementos formales de las antiguas arquitecturas existentes en el lugar, y por el contrario, opta por adoptar geometrías y volúmenes más acordes a las tendencias posmodernas propias de la arquitectura de 1980 y 90. Sin embargo, al revisar las imágenes de un ante proyecto publicado en la revista Proa de octubre de 1984, se descubre cómo inicialmente se había pensado en unas volumetrías más conservadoras, cuya imagen de conjunto, un tanto neutra invocara un sentido de modestia y austeridad propios del otrora barrio Santa Bárbara.
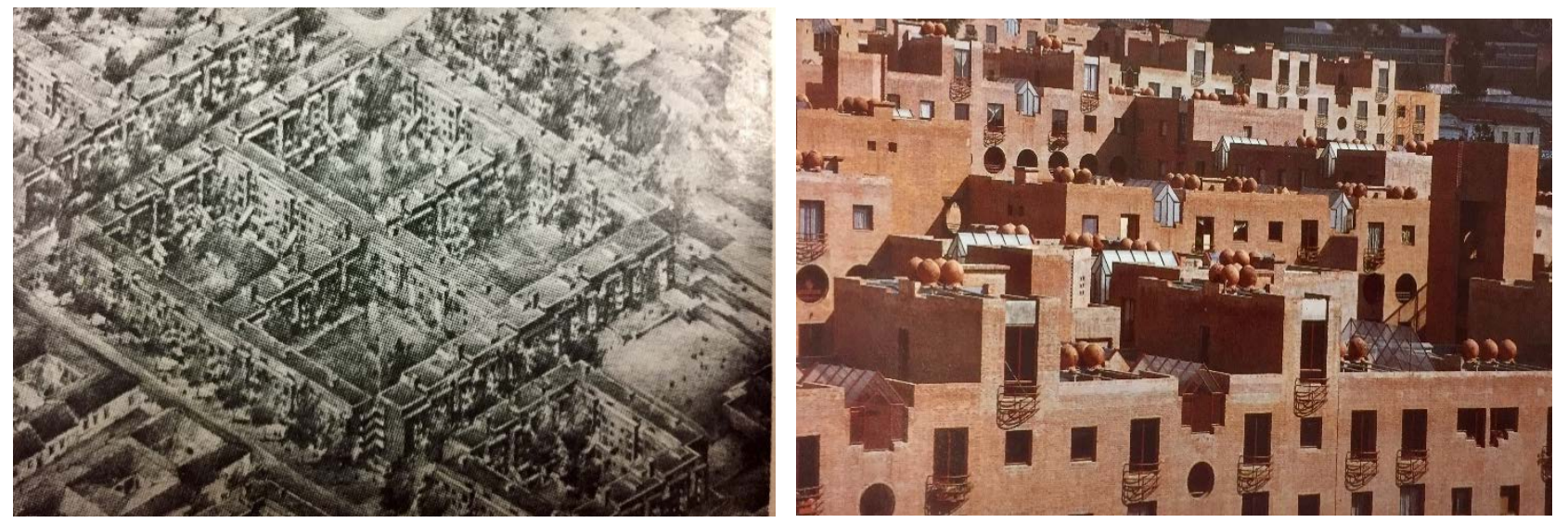

(1) Perspectiva Ante proyecto de Nueva Santa Fe de Bogotá (1984). Imagen Revista PROA (2) Foto general proyecto construido (2006) Imagen tomada del libro: Rogelio Salmona. Obra completa 1959 / 2005

Finalmente, y aunque se apostó por una imagen más posmoderna en la obra construida, se incluyeron estrategias proyectuales con las que se buscó rescatar al interior del proyecto la vida urbana del antiguo barrio Santa Bárbara, como las largas calles internas con vista a los centros de manzana que llevan a los usuarios a cada una de las unidades de vivienda, que promueven, en cada uno de los niveles del edificio, el encuentro espontáneo entre los habitantes del proyecto. Así mismo, los senderos diagonales que, a modo de calles internas, estaban pensados para conectar desde las esquinas abiertas de las manzanas con los barrios circundantes, a fin de integrar el nuevo proyecto con su contexto, calles que posteriormente fueron cerradas por los nuevos propietarios argumentando problemas de seguridad y control.

En esta tensión entre pasado y modernidad, el proyecto pareciera a primera vista, ser más cercano a esta última posición, empero, al recorrer sus calles externas se percibe una atmósfera sosegada en el entorno inmediato del conjunto, en tanto que al interior del mismo, los centros de manzana invocan el ambiente monástico de un claustro, por lo que pareciera que, aunque se densificó significativamente el barrio original, se logró conservar y prolongar el ambiente doméstico de tranquilidad, propio del antiguo barrio.

A pesar de todo lo anterior, es de reconocer que el postulado inicial del proyecto de "ciudad dentro de la ciudad", bajo el que se concibió Nueva Santa Fe de Bogotá, poco se cumplió debido a varios factores, el principal de ellos, que el proyecto no se llevó a cabo en su totalidad, pues apenas se construyeron 3 de las 9 manzanas proyectadas, "aunque el área intervenida fue de 8.8 has, y la construida de 6.7 has. se construyeron $56.850 \mathrm{~m} 2$ en vivienda y $10.650 \mathrm{~m} 2$ en equipamientos comunales y estacionamientos subterráneos,...",(Arias, 2010:112) así como tampoco se construyeron varios de los equipamientos previstos y que resultaban claves 
para la reactivación del sector. De estos equipamientos sólo se construyeron dos, uno, el Archivo General de la Nación, obra de Rogelio Salmona, y un segundo edificio dedicado a la Superintendencia de Sociedades, dos proyectos que poco se relacionan con la vida cotidiana del barrio, subrayando así su condición diferencial.

En contraste con las estrategias adoptadas por German Samper para la Ciudadela Colsubsidio, los modos de incorporar la historia como presencia viva dentro del proyecto por parte de Rogelio Salmona, no obedecen a una cuestión de evocaciones de tipo formal, sino de invocaciones, es decir, de llamados a la historia del lugar con los que el nuevo proyecto busca acogerse a las lógicas y patrones históricos prexistentes, un modo de homenaje a las antiguas arquitecturas, hecho con nueva arquitectura, conformando así lo que el historiador francés Pierre Nora define como un lugar de memoria, un espacio donde se cristaliza y se refugia la memoria colectiva, en este caso, de los habitantes del sector.

Puesto así, el reto de la Nueva Santa Fe de Bogotá fue el de invocar en el proyecto, "la historia que dio unidad al lugar", con el fin de que los futuros habitantes pudiesen evocarla sin caer en literalidades o historicismos. A este respecto y como ya se mencionó, las estrategias fueron de varios ordenes, algunas de carácter urbanístico, como mantener el trazado original en damero por medio de manzanas paramentadas, otras de carácter arquitectónico como la implementación de aleros, que cubren la circulación en los primeros niveles y acompañan la pendiente de la topografía.

\section{EPILOGO:}

Siete años después de haber sido diseñados los proyectos para Ciudadela Colsubsidio y Nueva Santa Fe de Bogotá, ya en 1991, Salmona y Samper participan -por separado- en el Concurso nacional de arquitectura y urbanismo Carlos Lleras Restrepo, un concurso destinado al diseño de un barrio previsto para albergar 3.000 viviendas, ubicado en un lote baldío del occidente de la ciudad.

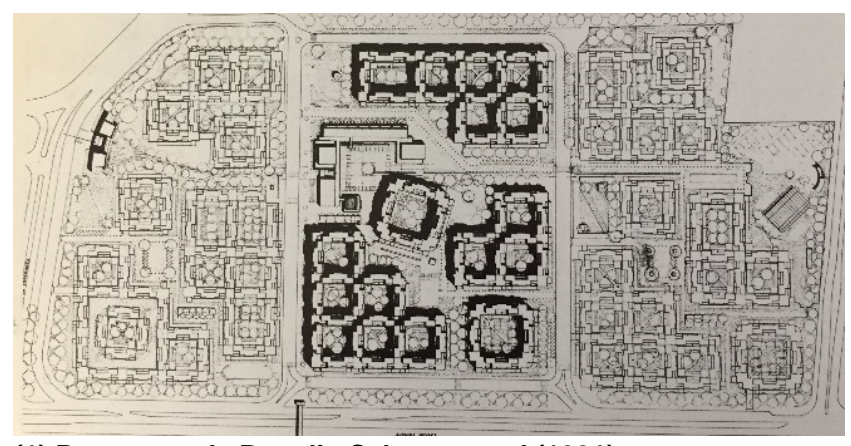

(1) Propuesta de Rogelio Salmona et al (1991)

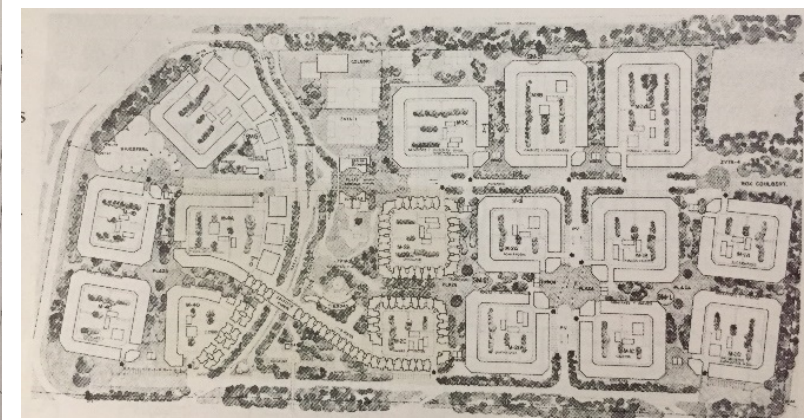

2) Propuesta de German Samper et al (1991)

Imágenes tomadas del libro: Concurso nacional de arquitectura y urbanismo Carlos Lleras Restrepo

Ninguno de los dos arquitectos gana el concurso, pero la visión de la ciudad futura expresada en sus propuestas, reafirma - en el caso de Salmona - una visión de la ciudad, concebida a partir de una noción morfológica de manzana con centro vacío, sumada, a una conciencia del paisaje urbano como dimensión contextual y cultural. Estas características, ya incorporadas en el proyecto de Nueva Santa Fe de Bogotá, se reiteran ahora en el proyecto presentado a concurso, en una confirmación de las ideas que le llevaron a Salmona a radicalizar aún más su noción de paisaje, aplicada al desarrollo urbano arquitectónico, a propósito de este concurso: "El paisaje urbano es a nuestro modo de ver, un punto esencial para el enriquecimiento de los fragmentos de ciudad, ocupados por proyectos de esta escala. En nuestros tiempos, debido a la extrema zonificación de usos urbanos y a la estandarización y deshumanización de la ciudad, ha disminuido la diversidad de las formas arquitectónicas y ha aumentado la astenia en los espacios urbanos" (Salmona 1991:35). 


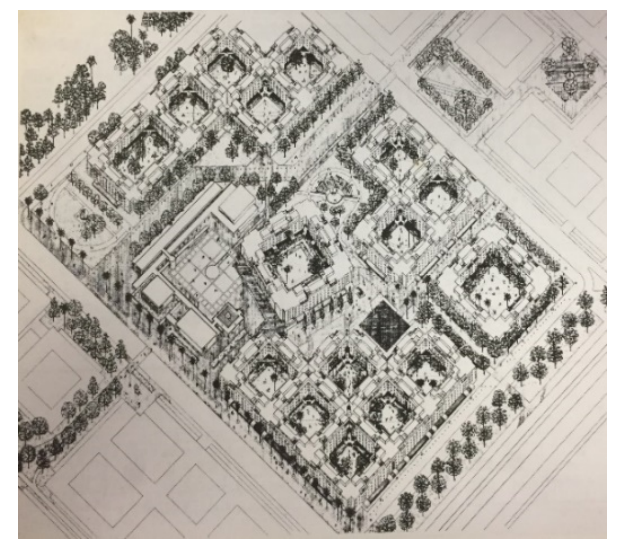

(1) Propuesta de Rogelio Salmona et al (1991) Imágenes tomadas del libro: Concurso nacional de arquitectura y urbanismo Carlos Lleras Restrepo

(2) Propuesta de German Samper et al (1991)

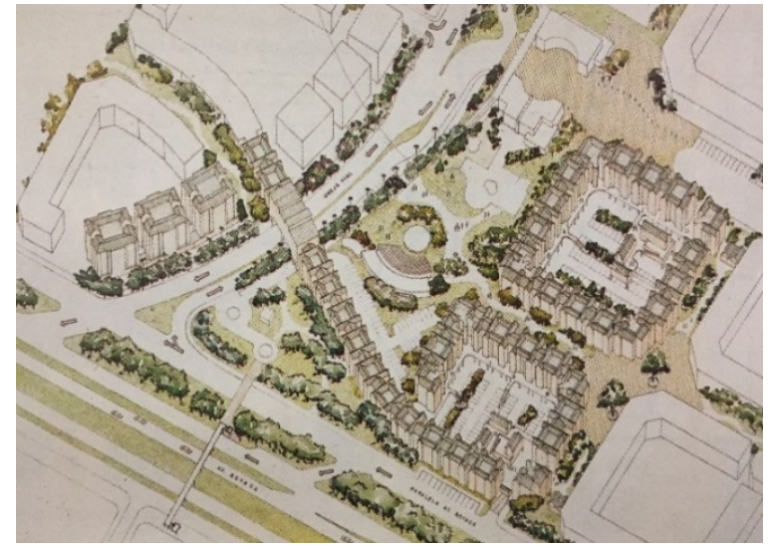

En la propuesta presentada a concurso por Germán Samper, se evidenciaría un profundo cambio en la aproximación al modo de entender el desarrollo urbano y el crecimiento de la ciudad, respecto al enfoque desarrollado en el caso de Ciudadela Colsubsidio, pues lejos de las evocadoras alusiones historiográficas que allí tuvieron lugar, en el proyecto presentado para este concurso se revela una aproximación de orden morfológico e historiográfico, más cercana a las ideas de Salmona, tal como se comprueba en la memoria descriptiva del proyecto presentado por Samper: "Como ley urbana invariable a través de los siglos, la manzana se mantiene como una constante, un módulo urbano único" ... "Nuestra propuesta consiste en rescatar la manzana como módulo urbano adaptándolo a las condiciones de la vida moderna de Bogotá." (Samper, 1991: 75), y, en consecuencia, el equipo liderado por Samper implanta en el terreno 16 manzanas ochavadas con patios centrales, dos de estas manzanas aparecen en el proyecto, interconectadas por un edificio-puente, en una estrategia que recuerda ya de lejos una tipología implementada desde tiempos inmemoriales y puesta de nuevo en boga durante el movimiento moderno en el Edificio para la Bauhaus en Dessau. En la implantación de estas manzanas se evita su alineación en ángulos de 90 grados, y por el contrario, se imbrican de manera aparentemente azarosa, a fin de generar perspectivas interiores y circulaciones menos rígidas al interior del proyecto.

Este balance comparativo en los modos de hacer ciudad en Colombia, y específicamente en Bogotá, a finales del siglo XX, expresa, desde las experiencias de Salmona y Samper, dos modos de entender el pasado como insumo proyectual para la ciudad futura, pero también, dos modos de entender y recuperar una historiografía del pasado como parte de una metodología proyectual originada en una experiencia en el dibujo de otras ciudades, de otras épocas. Esta metodología, planteada por Le Corbusier a sus entonces discípulos Salmona y Samper, revela en los distintos modos de adopción y adaptación, un aprendizaje y un saber críticos frente a los postulados Le Corbuserianos. En este sentido es importante hacer notar que, si bien desde distintos ángulos, hubo una aceptación por parte de Salmona y Samper acerca del dibujo como experiencia pedagógica en el modo de aprender y ver la arquitectura de la ciudad, propuesta por Le Corbusier, también hubo un amplio rechazo en el modo de concebir y diseñar la ciudad desde los preceptos del maestro suizo. Esta perspectiva crítica frente a las enseñanzas de su otrora mentor, es muestra de la necesidad e importancia que tenemos los arquitectos de ampliar nuestros horizontes conceptuales re-conociendo el acervo acumulado en otras latitudes y a la vez, la capacidad de desarrollar una conciencia propia frente a las particularidades y retos que nos impone nuestro propio contexto, nuestra propia realidad. 
BIBLIOGRAFIA:

\section{LIBROS}

SAMPER GERMAN. (1986) La arquitectura y la ciudad. Apuntes de Viaje. Bogotá: Escala.

TÉLLEZ GERMAN. (2006) Rogelio Salmona Obra completa 1959 / 2005. Bogotá: Escala.

DEPARTAMENTO NACIONAL DE PLANEACIÓN. Ciudades dentro de la ciudad. La política urbana y el plan de desarrollo en Colombia. (1974) Bogotá: Tercer Mundo

SAMPER GERMAN. (2003) La Evolución de la vivienda. Bogotá: Escala

SAMPER GERMAN. (2016) A Dibujar se aprende dibujando. Bogotá: Instituto Distrital de Patrimonio Cultural.

SAMPER GERMAN. (1997) Recinto urbano. La humanización de la ciudad. Bogotá: Escala.

BANCO CENTRAL HIPOTECARIO. SUBGERENCIA TÉCNICA (1986). Plan de renovación urbana Nueva Santa Fe de Bogotá. Bogotá: Escala

ARIAS FERNANDO (2010). La arquitectura de los barrios del Banco Central Hipotecario. 1953-1984. Bogotá: Universidad Nacional de Colombia.

FONDO NACIONAL DE AHORRO. (1991) Concurso nacional de arquitectura y urbanismo Carlos Lleras Restrepo. Bogotá: Escala

\section{REVISTAS}

PROA MONOGRAFÍAS 3 (1990). Rogelio Salmona Obra publicada en Proa. Bogotá: Proa.

PROA Arquitectura Diseño Urbanismo Industrias 335 (1984) Bogotá: Proa.

GARCÍA BEATRIZ. (1997) Arquitectura colombiana. En: Ensayos 4. Bogotá: Universidad Nacional de Colombia

SAMPER GERMAN. (2011) La arquitectura no tiene prisa. Nota Uniandina. Bogotá: UNIANDES 